\title{
Gold Ketenide
}

\author{
Ernest T. Blues, Derek Bryce-Smith and Ian W. Lawston
}

Department of Chemistry, University of Reading, England

\begin{abstract}
One of a new class of organometallic compounds, gold ketenide has an unusual structure and interesting properties. Gold films formed by its controlled thermal decomposition show possibilities as highly active and selective oxidation catalysts.
\end{abstract}

Metal ketenides of the formula $\mathrm{M}_{2} \mathrm{C}=\mathrm{C}=\mathrm{O}$, where $\mathrm{M}=\mathrm{Cu}, \mathrm{Ag}$ or $\mathrm{Au}$, are a new class of organometallic compounds $(1,2,3,4)$. These compounds are of interest because they provide the first examples of organometallic derivatives of the Group IB metals in which two metal atoms are linked to one carbon atom, and because of their high thermal stability relative to that of most other organometallic compounds of copper, silver and gold. The crystal structure of the silver compound has been established, and involves an unusual arrangement of closely bonded silver atoms in layers comprising an "infinite" square network lattice. From a practical viewpoint, the Group IB metal ketenides are of considerable interest because on suitable treatment they can give rise to highly active and selective oxidation catalysts.

\section{Preparation}

Gold ketenide, $\mathrm{Au}_{2} \mathrm{C}=\mathrm{C}=\mathrm{O}$, may be obtained in a pure state by reaction of ketene with a solution of chloro(1,4-oxathian)gold(I) in acetonitrile in the presence of an excess of 2,6-dimethylpyridine and triethylamine under dry argon at $-10^{\circ} \mathrm{C}$, N.m.r. evidence shows that the chloro-gold(I) precursor undergoes initial ligand exchange, Equation 1.

$$
\begin{aligned}
& \text { AuCl. } \mathrm{C}_{4} \mathrm{H}_{8} \mathrm{OS}+\mathrm{L} \rightleftharpoons \mathrm{AuCl} . \mathrm{L}+\mathrm{C}_{4} \mathrm{H}_{8} \mathrm{OS} \\
& \text { 2AuCl. } \mathrm{L}+\mathrm{CH}_{2}=\mathrm{C}=\mathrm{O}+2 \mathrm{NEt}_{3} \rightleftharpoons \\
& \mathrm{Au}_{2} \mathrm{C}=\mathrm{C}=\mathrm{O} . \mathrm{L}+2\left(\mathrm{Et}_{3} \mathrm{NH}\right)+\mathrm{Cl}^{-}+\mathrm{L} \\
& (\mathrm{L}=2,6 \text {-dimethylpyridine })
\end{aligned}
$$

The initial insoluble yellow product is a weak complex of gold ketenide with 2,6-dimethylpyridine, $\mathrm{Au}_{2} \mathrm{C}_{2} \mathrm{O}, \mathrm{C}_{7} \mathrm{H}_{9} \mathrm{~N}$, which readily loses the base on warming to $25^{\circ} \mathrm{C}$ to give pure gold ketenide as a dark-yellow, mildly-explosive, essentially amorphous, insoluble powder.

The use of a less sterically hindered heterocyclic tertiary base such as pyridine, monomethylpyridines or quinoline gives complexes analogous to the 2,6-dimethylpyridine complex having the same unusual stoicheiometry $\mathrm{Au}_{2} \mathrm{C}=\mathrm{C}=\mathrm{O}(\mathrm{L})$ with a single monodentate ligand molecule linked to two gold atoms, but from which complete removal of the ligand has not proved to be possible without some decomposition of the ketenide. Although the presence of triethylamine, or other strong tertiary base, is essential in the preparation, no complex of triethylamine with gold ketenide is obtained: presumably the function of the strong base is to remove the $\mathrm{HCl}$ from the system, Equation 2.

Omission of a heterocyclic base gives gold ketenide directly but in a less pure state than when prepared via its 2,6-dimethylpyridine complex. Acetic anhydride may serve as an in situ source of ketene if a large excess of triethylamine is used, Equation 3, but the rate of formation of gold ketenide or its complexes is slower and the yields are lower, as expected if the equilibria in equations 1,2 and 3 are involved.

$$
\begin{aligned}
\mathrm{R}_{3} \mathrm{~N}+\mathrm{Ac}_{2} \mathrm{O} & \rightleftharpoons \mathrm{R}_{3} \stackrel{+}{\mathrm{N}} \mathrm{COCH} \mathrm{OCA}_{3} \rightleftharpoons \\
\mathrm{R}_{3} \stackrel{+}{\mathrm{N} H} \mathrm{OA} \mathrm{A} & \stackrel{\mathrm{CH}_{2}}{=} \mathrm{C}=\mathrm{O}
\end{aligned}
$$

\section{Properties}

Gold ketenide* is a dark-yellow, light-sensitive solid, completely insoluble in all solvents so far examined other than those which cause decomposition. Gold ketenide is the least thermally-stable of the Group IB metal ketenides; it decomposes slowly above $50^{\circ} \mathrm{C}$ and explodes when exposed to a flame or is heated rapidly to about $110^{\circ} \mathrm{C}$. In contrast, silver ketenide when heated under the same conditions does not explode until $304^{\circ} \mathrm{C}$, although slow decomposition sets in at about $120^{\circ} \mathrm{C}$. In common with the other Group IB metal ketenides, gold ketenide may explode when struck or ground between hard surfaces, for example, on removal of the dry ketenide from a sintered glass filter by means of a metal spatula. The complexes of gold ketenide with heterocyclic bases are not shock-sensitive and burn with mild sputtering when exposed to a flame.

*Gold ketenide, in common with the other Group IB metal ketenides, is explosive in the dry state when heated strongly or struck, but is much less explosive than gold acetylide. 

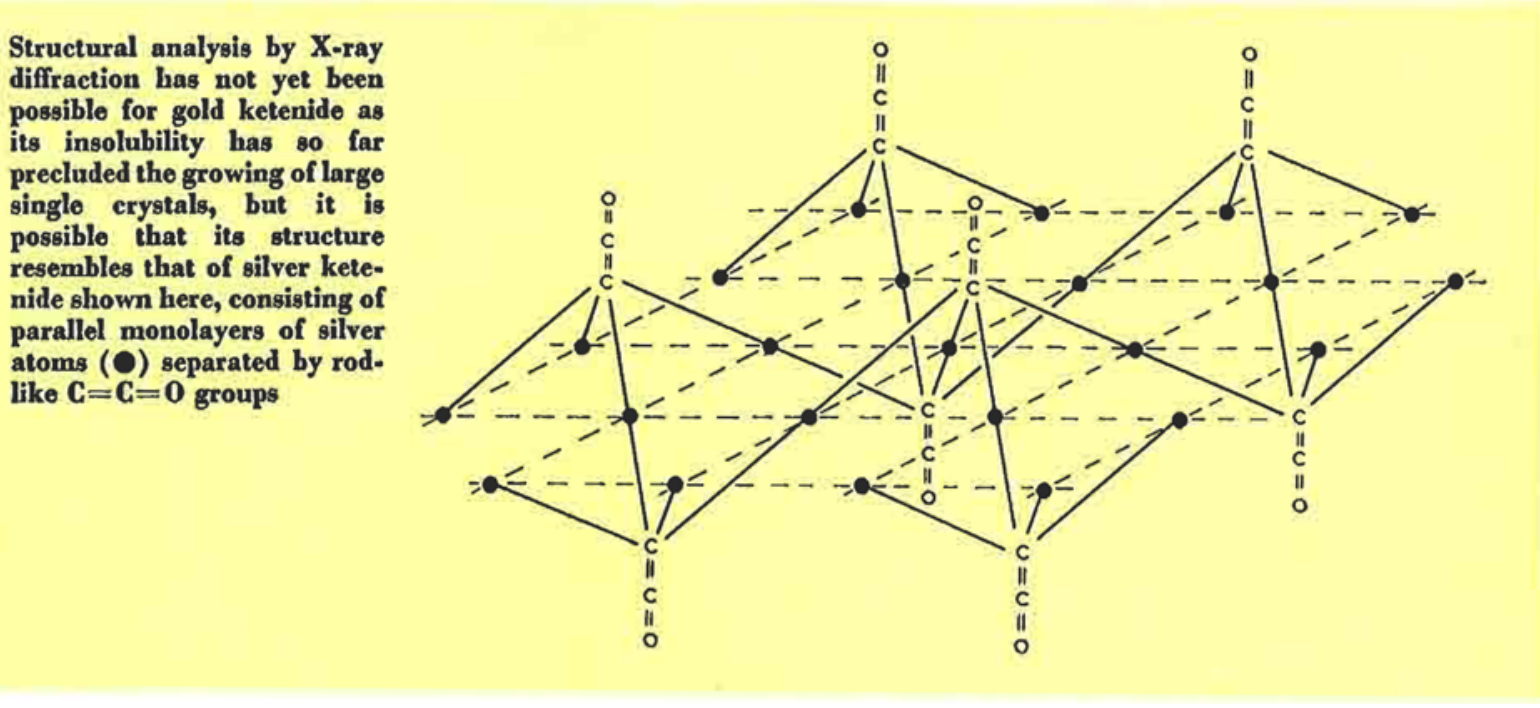

The complexes may explode however, when heated gradually to above $100^{\circ} \mathrm{C}$; presumably, partial loss of the heterocyclic base from the complex generates gold ketenide which may then explode.

The infrared spectrum of gold ketenide closely resembles those of silver and copper ketenides $(1,2)$. Observed absorption bands in the $400-4000 \mathrm{~cm}^{-1}$ region and their tentative assignments are: $428 \mathrm{~s}$ (vAu-C); $562 \mathrm{~m}$ ( $8 \mathrm{CCO}$ ), and $2015 \mathrm{vs}$ (vas CCO) $\mathrm{cm}^{-1}$. In the spectra of the complexes of gold ketenide with heterocyclic bases these absorption bands are all slightly shifted to lower wave numbers but are unsplit. Thus the gold ketenide pyridine complex, $\mathrm{Au}_{2} \mathrm{C}=\mathrm{C}=\mathrm{O}$.Py, shows major absorption bands at 420,552 and $1980 \mathrm{~cm}^{-1}$, together with absorption bands characteristic of coordinated pyridine. The strong absorption bands in the spectra of gold ketenide and its pyridine-complex at 428 and $420 \mathrm{~cm}^{-1}$ respectively, imply that the Au-C bonds are essentially covalent. The absence of splitting of these absorption bands implies that both Au-C bonds are equivalent, even in the pyridine complex in spite of its unique stoicheiometry among complexes of gold(I) compounds with monodentate ligands. Copper and silver ketenides also form pyridine complexes having the same unusual stoicheiometry $\mathrm{M}_{2} \mathrm{C}=\mathrm{C}=\mathrm{O} . \mathrm{Py}(\mathrm{M}=\mathrm{Cu}, \mathrm{Ag}, \mathrm{Au})$.

\section{Structure}

The insolubility of gold ketenide and its complexes with heterocyclic bases in all solvents so far investigated has precluded the growing of large single crystals suitable for structural analysis by $\mathrm{X}$-ray diffraction. Attempts to index the X-ray powder diffraction patterns of gold ketenide and its pyridine complex, successful in the case of the corresponding silver compounds (1), failed because of their poor crystallinity. It is therefore not possible to say whether gold and silver ketenides are isostructural although the close similarity in size of silver and gold metallic radii (1.442 and $1.439 \AA$ respectively) (5) and the same unusual stoicheiometry of their pyridine complexes suggests that this is possible. Silver ketenide has a unique structure, shown above, involving infinite monoatomic layers of silver atoms arranged in a square network. The $\mathrm{Ag}-\mathrm{Ag}$ distance is $2.84 \AA$, which is slightly shorter than the corresponding distance between adjacent silver atoms in normal face-centred, cubic, silver metal $(2.885 \AA)$ : one might describe such a layer of silver atoms as a two-dimensional metal or, alternatively, as a giant metal "cluster". Parallel monolayers of silver atoms have a separation of $5.846 \AA$, and are separated by rod-like $\mathrm{C}=\mathrm{C}=\mathrm{O}$ groups, the axes of which are perpendicular to the layers of silver atoms, and which are symmetrically disposed in an alternating manner on each side of a silver layer as shown. The pyridine complex of silver ketenide also has a layer structure closely related to that of silver ketenide. The silver atom layers are almost identical in both compounds except that in $\mathrm{Ag}_{2} \mathrm{C}_{2} \mathrm{O}$.Py the $\mathrm{Ag}-\mathrm{Ag}$ distance $(2.85 \AA)$ is slightly larger, although still less than in silver metal. The interlayer separation in the pyridine complex is, however, more than doubled at $12.09 \AA$ to accommodate the pyridine molecules which have their two-fold symmetry axes perpendicular to the silver layers and parallel to the axes of the ketenide groups. The unusual stoicheiometry of the pyridine complex is imposed at least in part by steric reasons, as the structure will only accommodate one pyridine molecule for every two silver atoms. One is tempted to assume that the similar stoicheiometry of the pyridine complex of gold ketenide results from a similar restricted structure containing monolayers of gold atoms. A number of structural forms of silver ketenide are 
known, one of which resembles gold ketenide in being amorphous and is believed to have its ketenide groups arranged in a relatively random manner on each side of a given plane of silver atoms. The structure of uncomplexed gold ketenide may well be similar.

\section{Reactions of Gold Ketenide}

The chemistry of gold ketenide has not yet been extensively investigated but appears to parallel that of the other Group IB metal ketenides $(1,2,3)$. In particular, explosive decomposition of gold ketenide under argon at reduced pressure gives carbon suboxide as the major gaseous product. This unexpected mode of decomposition, Equation 4, is peculiar to all the Group IB metal ketenides.

$$
\begin{aligned}
& 2 \mathrm{M}_{2} \mathrm{C}=\mathrm{C}=\mathrm{O} \stackrel{\Delta}{\rightarrow} \mathrm{O}=\mathrm{C}=\mathrm{C}=\mathrm{C}=\mathrm{O}+\mathrm{C}+4 \mathrm{M} \quad 4 \\
& \mathrm{M}=\mathrm{Cu}, \mathrm{Ag}, \mathrm{Au}
\end{aligned}
$$

The mechanism by which carbon suboxide is produced in such decomposition is uncertain. It is possible that the initial product is carbonyl ketene, $\mathrm{C}=\mathrm{C}=\mathrm{O}$, and that carbon suboxide is formed by interaction of this with carbon monoxide (as is known to occur in other systems). Carbon monoxide can indeed be detected in small amounts in the gaseous products.

$$
\begin{aligned}
& \mathrm{Au}_{2} \mathrm{C}=\mathrm{C}=\mathrm{O} \rightarrow 2 \mathrm{Au}+\mathrm{C}=\mathrm{C}=\mathrm{O} \\
& \mathrm{C}=\mathrm{C}=\mathrm{O} \rightarrow \mathrm{C}+\mathrm{CO} \\
& \mathrm{C}=\mathrm{C}=\mathrm{O}+\mathrm{CO} \rightarrow \mathrm{O}=\mathrm{C}=\mathrm{C}=\mathrm{C}=\mathrm{O}
\end{aligned}
$$

Another reaction undergone by gold ketenide characteristic of Group IB metal ketenides is that with acetylene or mono-substituted acetylenes to give the corresponding acetylide and ketene, Equation 8 .

$$
\begin{gathered}
\mathrm{M}_{2} \mathrm{C}=\mathrm{C}=\mathrm{O}+2 \mathrm{RC} \equiv \mathrm{C}-\mathrm{H} \rightarrow 2 \mathrm{R}-\mathrm{C} \equiv \mathrm{C}-\mathrm{M}+ \\
\mathrm{CH}_{2}=\mathrm{C}=\mathrm{O} \\
\mathrm{M}=\mathrm{Cu}, \mathrm{Ag}, \mathrm{Au}
\end{gathered}
$$$$
\mathrm{CH}_{2}=\mathrm{C}=\mathrm{O} \quad 8
$$

Gold ketenide is more reactive than the other Group IB metal ketenides towards water and decomposes to gold metal within several hours. This relative instability of gold ketenide in water is probably due more to the inherent instability of gold(I) compounds not containing stabilising ligands such as phosphines than to enhanced reactivity of the ketenide group.

\section{Oxidation Catalysts \\ Derived from Ketenides}

Pyrolysis of silver ketenide and complexes of cuprous chloride with copper ketenide can provide highly selective catalysts for the oxidation of organic compounds-particularly olefins-by molecular oxygen under mild conditions (1-3). The silver obtained in this way has anomalous magnetic properties which appear to result from the presence of micelles which inherit to some degree the lamellar metal-metal bonded structure of the ketenide precursor. It has been found that the gold metal obtained by controlled thermal decomposition of gold ketenide has interesting and unusual properties as a selective catalyst for the air-oxidation of propylene to propylene oxide. Thus, decomposition of gold ketenide on a glass support at $100^{\circ} \mathrm{C}$ under propylene gives tightly adhering films of gold metal which catalyse the airoxidation of propylene at $215^{\circ} \mathrm{C}$ giving propylene oxide as the major organic product with traces of acrolein, and with selectivities (propylene oxide/ propylene oxide $+\mathrm{CO}_{2}$ ) in the range 20 to 50 per cent. The proportion of acrolein increases with increase in temperature.

This catalytic behaviour contrasts with that previously reported for gold metal prepared in a more conventional manner by thermal decomposition of chloroauric acid. Such gold metal, supported on non-porous silica gel or used as a metal sponge, catalysed the air-oxidation of propylene to acrolein ( 50 per cent) and acetone ( 3 per cent) but gave no propylene oxide (6). Earlier workers had reported that air-oxidation of propylene over gold films of unspecified origin gave only carbon dioxide and water (7). The difference in catalytic activity of gold metal formed by decomposition of gold ketenide from that reported by previous workers for gold suggests that there are differences in the surface structure such as defects or high energy regions which lead to altered absorption characteristics. By analogy with silver it is tempting to speculate that the "active" gold obtained from gold ketenide inherits to some degree a metal-metal bonded cluster structure present in the precursor. This possibility is at present under investigation.

\section{References}

1 E. T. Blues, D. Bryce-Smith, H. Hirsch and M. J. Simons, Chem. Commun., 1970, (11), 699; D. BryceSmith and E. T. Blues, British Patent 1,295,641, 1970

2 E. T. Blues, D. Bryce-Smith, B. R. Kettlewell, M. Roy and others, F. Chem. Soc., Chem. Commun., 1973, (23), 921; D. Bryce-Smith and E. T. Blues, British Patent $1,329,252,1971$

3 E. T. Blues, D. Bryce-Smith, I. W. Lawston and G. D. Wall, $\mathcal{F}$. Chem. Soc., Chem. Commun., 1974, (13), 513; D. Bryce-Smith and E. T. Blues, British Patent 1,409,421, 1973

4 D. Bryce-Smith, Chem. \& Ind., 1975, (4), 154

5 L. Pauling, "The Chemical Bond", Oxford University Press, London, 1967

6 N. W. Cant and W. K. Hall, भ. Phys. Chem., 1971, 75, (19), 2914

7 W. R. Patterson and C. Kemball, f. Catalysis, 1963, 2, (6), 465 